\title{
Fetal colon diameter as a tool for estimating gestational age in advanced pregnancy in north Indian population: a pilot study
}

\author{
Renu Arora*, Nikky Punia, Archana Kumari
}

Department of Obstetrics and Gynaecology, Vardhman Mahavir Medical College and Safdarjung Hospital, New Delhi, 110029, India

Received: 11 March 2016

Accepted: 09 April 2016

*Correspondence:

Dr. Renu Arora,

E-mail: renuarora2010@yahoo.co.in

Copyright: (c) the author(s), publisher and licensee Medip Academy. This is an open-access article distributed under the terms of the Creative Commons Attribution Non-Commercial License, which permits unrestricted non-commercial use, distribution, and reproduction in any medium, provided the original work is properly cited.

\begin{abstract}
Background: Conventional Ultrasound dating is not very accurate after 34 weeks of gestation and has standard deviation of about 2 weeks. The aim of the study was to verify whether fetal colon diameter can be used as a tool for estimating gestational age (GA) of fetuses between 32 to 40 weeks.

Methods: 100 healthy pregnant women aged 20-35 years were recruited. Fetal bi-parietal diameter, head circumference, abdominal circumference, and femoral lengths were assessed by ultrasound. In addition descending colon diameter was assessed at the level of colonic haustra. The correlation between GA and colon thickness was assessed by the Pearson correlation test.

Results: Significant correlation between fetal colon diameter and maternal gestational age was observed $(\mathrm{r}=0.582)$. Correlation between gestational age and femur length $(r=0.725)$ was found to be higher than that between gestational age and colon diameter $(r=0.528)$ suggesting that femur length is a better parameter than colon diameter for gestational age estimation. The regression equation for gestational age as a function of colon diameter was derived as $\mathrm{GA}=28.614+0.629 \times \mathrm{CD}$. The diagnostic accuracy of CD of $\geq 12 \mathrm{~mm}$ in predicting term pregnancy was $75 \%$ with a high negative predictive value of $88.9 \%$ and positive predictive value of $58.7 \%$.

Conclusions: The present study suggested that colon diameter can be used for predicting term pregnancy. Further studies are required to validate this novel marker of maturity amongst Indian population.
\end{abstract}

Keywords: Colon thickness, Fetal colon, Gestational age, Ultrasound

\section{INTRODUCTION}

Pregnancies with an unknown last menstrual period, and without ultrasound evaluation before 28 weeks' gestation, may present a dilemma to obstetricians. Ultrasound dating is not very accurate after 34 weeks of gestation with standard deviation of about 2 weeks. ${ }^{1}$ Although many anthropometric measurements of the fetus have been proposed for the evaluation of fetal age in late pregnancy, none of them are accurate when taken for the first time during the third trimester of pregnancy because of significant biologic variability in fetal size. ${ }^{2}$
Colonic haustra can be identified in nearly all fetuses by the middle of the third trimester. The diameter of the large bowel increases in linear fashion from 3 to $5 \mathrm{~mm}$ at 20 weeks' gestation to up to $20 \mathrm{~mm}$ at term. Recently, interest has been shown by researchers Fetal colon diameter has been used in certain studies not only for pregnancy dating in the third trimester but also for diagnosis of fetuses small and large for date at gestational age 36 weeks onwards. ${ }^{3-6}$

The aim of the proposed study was to determine whether fetal colon diameter can be used as an independent parameter for estimating gestational age in third 
trimester. This might help in better estimation of gestational age in late pregnancy when other conventional methods of assessment of gestational age are not accurate.

\section{METHODS}

This prospective and cross-sectional study was conducted in the Department of Obstetrics and Gynaecology along with the Department of Radiology, Vardhman Mahavir Medical College and Safdarjung Hospital, New Delhi between July 2011 and December 2012.During this period, 100 pregnant women aged 20 to 35 years and between 32 to 40 weeks of pregnancy were recruited from the ANC OPD after ethical clearance from the institution. Written informed consent was obtained from all of the women before the study.

The study group consisted of pregnant women who fulfilled the following criteria:

1. History of regular menses with a known date of the beginning of the last menstrual period;

2. Confirmed gestational age based on sonographic measurement of the crown-rump length in early pregnancy;

3. Clinically and sonographically normal fetus.

Each patient was scanned only once during the study by a single experienced sonographer using a transabdominal 3.5-5.0-MHz curvilinear transducer. The fetal colon was identified sonographically by its peripheral location and characteristic haustral folds. The maximum internal diameter of the fetal descending colon was measured in the parasagittal plane (Figure 1).

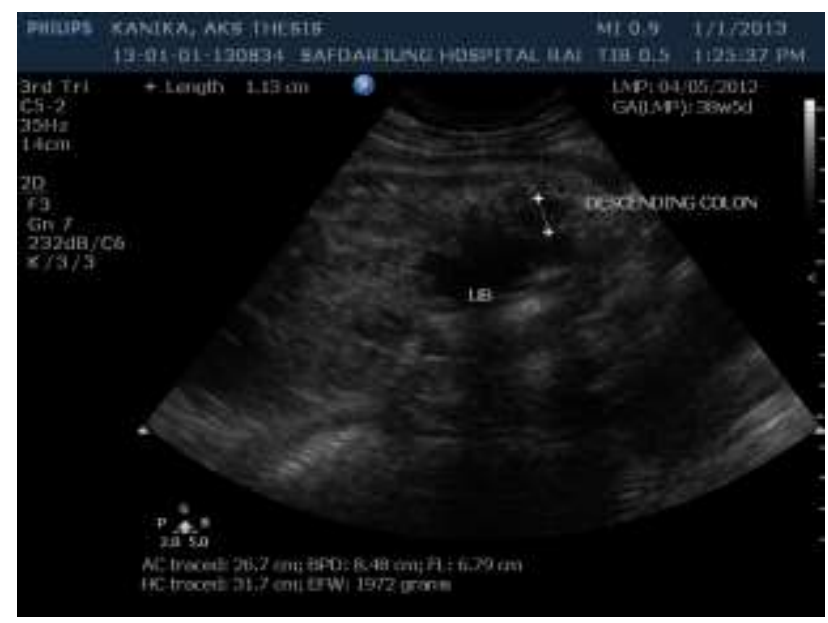

Figure 1: Maximum internal diameter of the fetal descending colon in the parasagittal plane.

Each measurement was repeated three times in each fetus and the largest diameter was recorded. Freeze-frame ultrasound capabilities and electronic on-screen calipers were used for the bowel measurements. The measurement of fetal colon diameter was followed by biometric measurements like biparietal diameter, head circumference, abdominal circumference and femur length. For measuring the femur length, only the ossified portions of the diaphysis and metaphysis were measured while maintaining proper alignment of the transducer which was ensured by demonstrating that both the femoral head or the greater trochanter and the femoral condyl were simultaneously in the plane of section.

Once these measurements were made, these women were followed up till their delivery and the maternal and fetal outcomes in terms of morbidities like development of any medical or obstetric complications, and birth asphyxia or IUGR in the new-born were noted.

\section{Statistical analysis}

Categorical variables were analysed using Chi square test or the Fissure Exact test. These included the term or preterm fetuses, presence or absence of IUGR, etc. Quantitative values were analysed by the unpaired t-test or ANOVA. These included age distribution, weight, height, body mass index, biparietal diameter, head circumference, abdominal circumference, femur length and colon diameter, etc. Comparison between quantitative variables was done with help of Pearson correlation coefficient. P-value of less than 0.05 was considered significant. The means and $95 \%$ confidence intervals (CIs) of the diameters of the colon for consecutive gestational ages were calculated. The data was analysed by SPSS statistical software version 16.0.

\section{RESULTS}

The mean age of all the participants was $24.06 \pm 2.96 \mathrm{yrs}$ of which $69 \%$ were < 25 years of age, $25 \%$ were between 25-29 years while only $6 \%$ were $>30$ years. Of all the participants $33 \%$ were between $37-40$ weeks of gestation. There was a linear correlation between gestational age and femur length $(r=0.725)$ and between gestational age and colon diameter $(r=0.582)$ as shown in Figure 2.

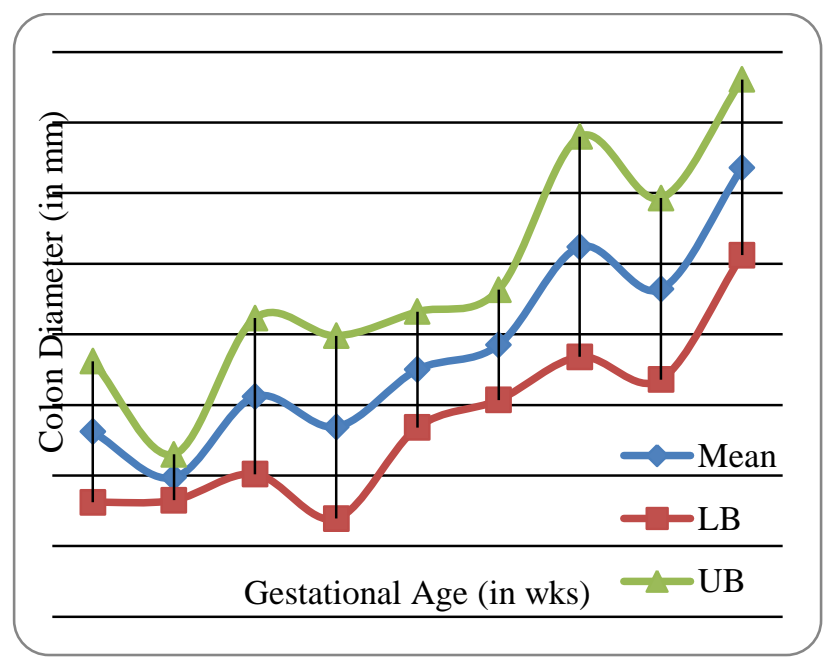

Figure 2: Relationship of fetal colon diameter to gestational age. 
A linear correlation was also found between femur length and colon diameter $(r=0.632)$. The regression equations for gestational age as a function of femur length and as a function of colon diameter were calculated as shown in Table 1.
Table 1: Regression equations.

\begin{tabular}{|lll|}
\hline Parameter & Regression equation & $\mathbf{R}^{2}$ \\
\hline Femur length & $\mathrm{GA}=9.317+3.915 \times \mathrm{FL}$ & 0.525 \\
\hline Colon diameter & $\mathrm{GA}=28.614+0.629 \times \mathrm{CD}$ & 0.339 \\
\hline
\end{tabular}

Table 2: Diagnostic accuracy of $\mathrm{CD}$ in predicting a GA of $\geq 37$ weeks.

\begin{tabular}{|llllll|}
\hline Colon diameter & Sensitivity & Specificity & \multicolumn{2}{l}{$\begin{array}{l}\text { Positive predictive } \\
\text { value }\end{array}$} & $\begin{array}{l}\text { Negative } \\
\text { predictive value }\end{array}$ \\
\hline$\geq 12 \mathrm{~mm}$ & $81.8 \%$ & $71.6 \%$ & $58.7 \%$ & $88.9 \%$ & $75 \%$ \\
\hline$\geq 14 \mathrm{~mm}$ & $33.3 \%$ & $91 \%$ & $64.7 \%$ & $73.5 \%$ & $72 \%$ \\
\hline $16 \mathrm{~mm}$ & $12.1 \%$ & $100 \%$ & $100 \%$ & $69.8 \%$ \\
\hline
\end{tabular}

The diagnostic accuracy of $\mathrm{CD}$ of $\geq 11 \mathrm{~mm}$ in predicting a GA of $\geq 34$ wks was $65 \%$ with sensitivity and specificity of $65.4 \%$ and $63.2 \%$ respectively.

Comparison of colon diameters of the term and preterm fetuses among the IUGR and non-IUGR population revealed a statistically significant difference only in term pregnancies ( $p$-value 0.02). For the preterm fetuses, the mean colon diameter for IUGR and non-IUGR fetuses was found to be $10.59 \mathrm{~mm}$ and $11.24 \mathrm{~mm}$ respectively. At p-value 0.18 , this difference was not statistically significant (Table 4).

Table 3: Femur length and colon diameter in preterm and term foetuses.

\begin{tabular}{|c|c|c|c|c|c|c|c|}
\hline Gestational age & $\mathbf{N}$ & $\begin{array}{l}\text { Mean FL } \\
\text { (in cm) }\end{array}$ & $95 \%$ CI & p-value & $\begin{array}{l}\text { Mean CD } \\
\text { (in mm) }\end{array}$ & $95 \% \mathrm{CI}$ & p-value \\
\hline $\operatorname{Preterm}(<37$ wks $)$ & 67 & 6.67 & $6.59-6.76$ & \multirow{2}{*}{$<0.001$} & 11.10 & $10.69-11.51$ & \multirow[b]{2}{*}{$<0.001$} \\
\hline $\operatorname{Term}(\geq 37 \mathrm{wks})$ & 33 & 7.17 & $7.04-7.31$ & & 13.33 & $12.59-14.07$ & \\
\hline
\end{tabular}

Table 4: Comparison between IUGR and non-IUGR foetuses.

\begin{tabular}{|l|lllll|}
\multicolumn{1}{r}{ Gestational age } & \multicolumn{3}{c}{ IUGR } & \multicolumn{3}{c|}{ Non-IUGR } \\
& $\begin{array}{l}\text { Mean CD } \\
\text { (in mm) }\end{array}$ & $\begin{array}{l}95 \% \text { CI } \\
\text { (in mm) }\end{array}$ & $\begin{array}{l}\text { Mean CD } \\
\text { (in mm) }\end{array}$ & $\begin{array}{l}95 \% \text { CI } \\
\text { (in mm) }\end{array}$ & $\begin{array}{l}\text { p- } \\
\text { value }\end{array}$ \\
\hline Preterm(<37 wks) & 10.59 & $9.52-11.65$ & 11.24 & $10.80-11.70$ & 0.18 \\
\hline Term( $\geq 37$ wks) & 12.00 & $10.88-13.12$ & 13.83 & $12.94-14.72$ & 0.02 \\
\hline
\end{tabular}

\section{DISCUSSION}

It is not unusual in our daily clinical practice to find patients visiting OPDs in the last trimester without known last menstrual period and a dating ultrasound done in the first trimester. Besides, most of them present to the hospital only in the late pregnancy when any complication has already occurred mandating correct evaluation of fetal maturity. An overestimation of gestational age even by a few days will erroneously designate a normally grown infant as growth compromised and underestimation will lead to false categorization of growth compromised infant as normally grown. ${ }^{7}$ Ultrasound has been a very reliable tool for estimating the gestational age especially in the first half of pregnancy. ${ }^{8,9}$ However in the third trimester, the calculation of gestational age by routine biometrics is not as reliable and the disparity is up to two to three weeks. ${ }^{10}$ Although many studies have been done among western population to determine the relationship between various features of the intestinal development and the gestational

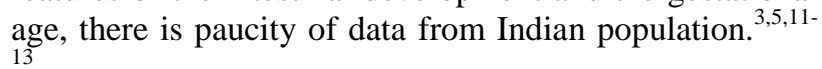

In this study, we have studied the relationship of maximum diameter of the fetal descending colon with the gestational age between 32 to 40 weeks of gestation and tried to verify whether fetal colon diameter can be used for estimating the gestational age of fetuses among Indian population.

We observed variation in colon diameter at each gestational age, in agreement with the results of Hertzberg et al Colon diameter demonstrated a linear relationship with gestational age. ${ }^{14}$ A statistically significant correlation was achieved between the third trimester gestational age and the maximum internal diameter of the fetal descending colon $(r=0.582)$ although this correlation was not as high as that found by de Carvalho et al $(\mathrm{r}=0.77)$, Nyberg et al $(\mathrm{r}=0.82)$, Zalel et al $\left(r^{2}=0.84\right)$ or Goldstein et al $\left.\left(r^{2}=0.85\right)\right)^{3,5,12,13}$ 
In the present study, the mean colon diameter at 37 weeks of gestation was $11.85 \mathrm{~mm}$ and at 40 weeks it was 14.36 $\mathrm{mm}$. The maximum and minimum descending colon diameters for term pregnancies were $18.6 \mathrm{~mm}$ and 9.9 $\mathrm{mm}$, respectively. These results were similar to the findings of Zalel et al and Nyberg et al who found that colon diameter demonstrated a linear relationship with menstrual age, reaching a maximum of $18 \mathrm{~mm}$ at term. $^{12,13}$

In this study, we found that for fetuses with colon diameter equal to or greater than $12 \mathrm{~mm}, 58.7 \%$ were 37 weeks or older, with a sensitivity of $81.8 \%$ and specificity of $71.6 \%$. For fetuses with colon diameter equal to or greater than $14 \mathrm{~mm}, 64.7 \%$ were 37 weeks or older with a sensitivity of $33.3 \%$ and specificity of $91.0 \%$. In a study by Carvalho et al[5], they found that fetuses with colon diameter equal to or greater than $14 \mathrm{~mm}, 86.6 \%$ were 37 weeks or older. In our study, for fetuses with colon diameter equal to or greater than $16 \mathrm{~mm}, 100 \%$ were 37 weeks or older, with a sensitivity of $12.1 \%$ and specificity of $100 \%$.

A significant difference was found for the value of colon diameter among the preterm and term pregnancies ( $\mathrm{p}$ value 0.001 ). The mean colon diameter for term and preterm population was $13.33 \mathrm{~mm}$ and $11.10 \mathrm{~mm}$ respectively. The maximum and minimum values in the preterm group were $15.3 \mathrm{~mm}$ and $7.3 \mathrm{~mm}$ respectively and for term pregnancies these were $18.6 \mathrm{~mm}$ and 9.9 $\mathrm{mm}$, respectively.

In the present study, it was observed that in IUGR fetuses, the growth of colon was affected and suppressed in the last few weeks of gestation. Hence, measurements of colon diameter would not be helpful in differentiating a term fetus from an IUGR fetus at gestational age more than 37 weeks. In the study by Carvalho et al, they found statistically different mean colon diameter between IUGR and non-IUGR fetuses at 37 weeks, but not at 38 weeks. ${ }^{5}$

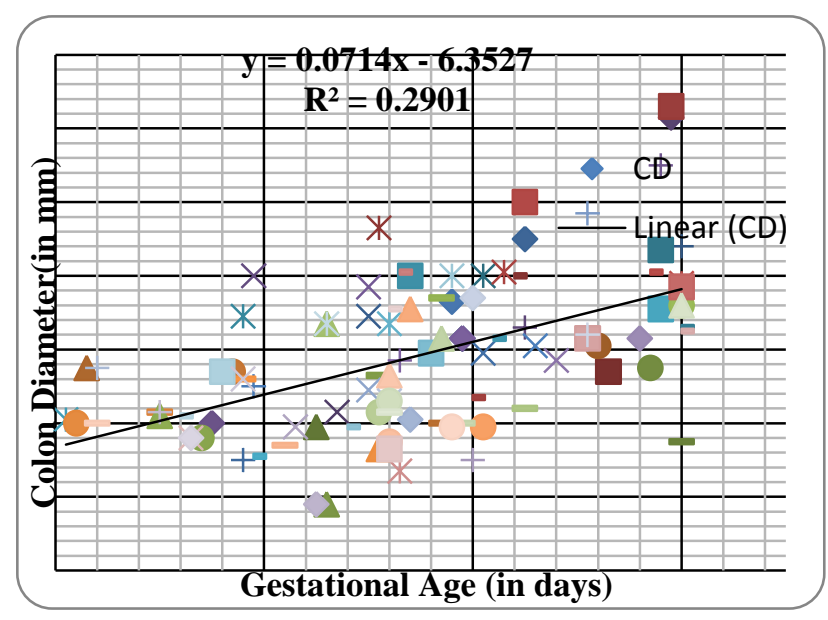

Figure 3: Correlation between colon diameter and gestational age in present study.
Comparing the results of present study with that of de Carvalho et al, linear correlation was found between colon diameter and gestational age in both the studies (Figure 3). ${ }^{5}$

The correlation between gestational age and femur length ( $r=0.725)$ was found to be higher than that between gestational age and colon diameter $(r=0.528)$ indicating that as an independent marker for gestational age estimation, femur length is a better parameter when compared with colon diameter. A linear correlation was also found between femur length and colon diameter $(\mathrm{r}=$ 0.632).

We formulated regression equations for these two parameters keeping gestational age as the dependent variable.

$\mathrm{GA}=9.317+3.915 \times \mathrm{FL}$

$\mathrm{GA}=28.614+0.629 \times \mathrm{CD}$

With this, we also found that $52.2 \%$ variation in gestational age could be explained due to variation in femur length. Likewise, $33.9 \%$ variation in gestational age could be explained due to variation in colon diameter.

The present study has limitations. In this study, fetuses with severe IUGR were not included. Further studies to assess the effect of severe IUGR on colon diameter are recommended. Furthermore, none of our patients had dilated bowel loops. Anal atresia, meconium plug syndrome, Hirschsprung's disease and other colorectal malformations are all sonographically visualized as dilated or hyperechogenic fetal colon. Whenever dilated bowel loops are suspected, a detailed sonographic evaluation should be carried out in order to exclude additional malformations.

This study is probably the first one of its kind done on the Indian population. The mean colon diameter found in the present study is smaller than that reported in western literature which may be contributed to the different growth potential of Indian fetuses. Thus a customization for Indian population is required. At this stage, the results of this study cannot be recommended for using colon diameter as an independent parameter for gestational age estimation. Furthermore femur length was found to best correlate with gestational age contrary to that reported in earlier studies. More and larger studies are recommended for the Indian population. Also, the sensitivity and specificity of colon diameter for estimating gestational age may be higher if non-biometric characteristics of fetal intestines like echogenicity grade of the colon, grade of small intestinal peristalsis and the presence or absence of colonic haustrations are also included in the study.

Funding: Not required

Conflict of interest: None declared

Ethical approval: The study was approved by the Institutional Ethics Committee 


\section{REFERENCES}

1. Lohr PA, Reeves MF, Creinin MD. A comparison of Transabdominal and transvaginal ultrasonography for determination of gestational age and clinical outcomes in women undergoing early medical abortion. Contraception. 2010;81(3):240-4.

2. Gottlieb AG, Galan HL. Nontraditional sonographic pearls in estimating gestational age. Semin Perinatol. 2008;32(3):154-60.

3. Goldstein I, Lockwood C, Hobbins JC. Ultrasound assessment of fetal intestinal development in the evaluation of gestational age. Obstet Gynecol. 1987;70(5):682-6.

4. Nyberg DA, Abuhamad A, Ville Y. Ultrasound assessment of abnormal fetal growth. Semin Perinatol. 2004;28(1):3-22.

5. de Carvalho AA, Marchiori E, Carvalho JA, Figueiredo I, Velarde LG. Use of fetal colon thickness for auxillary term dating of pregnancy. Int J Gynecol Obstet. 2011;112(3):216-9.

6. Loret de Mola JR, Judge N, Entsminger C, Deviney M, Muise KL, Duchon MA. Indirect prediction of fetal lung maturity. Value of ultrasonographic colonic and placental grading. J Reprod Med. 1998;43(10):898-902.
7. Maulik D. Fetal growth compromise: definitions, standards and classification. Clin Obstet Gynecol. 2006;49(2):214-8.

8. Kalish RB, Chervenak FA. Ultrasound assessment of gestational age. Optimal Obstetrics. 2002;1(2):1-6.

9. Mongelli M, Yuxin NG, Biswas A, Chew S. Accuracy of ultrasound dating formulae in the late second-trimester in pregnancies conceived with invitro fertilization. Acta Radiol. 2003;44(4):452-5.

10. Doubilet PM, Benson CB. Improved prediction of gestational age in the late third trimester. J Ultrasound Med. 1993;12(11):647-53.

11. Zilianti M, Fernández S. Correlation of ultrasonic images of fetal intestine with gestational age and fetal maturity. Obstet Gynecol. 1983;62(5):569-73.

12. Zalel Y, Perlitz Y, Gamzu R, Peleg D, Ben-Ami M. In-utero development of the fetal colon and rectum: sonographic evaluation. Ultrasound Obstet Gynecol. 2003;21(2):161-4.

13. Nyberg DA, Mack LA, Patten RM, Cyr DR. Fetal bowel. Normal sonographic findings. J Ultrasound Med. 1987;6(1):3-6.

14. Hertzberg BS. Sonography of the fetal gastrointestinal tract: anatomic variants, diagnostic pitfalls, and abnormalities. Am J Roentgenol. 1994;162(5):1175-82.

Cite this article as: Arora R, Punia N, Kumari A. Fetal colon diameter as a tool for estimating gestational age in advanced pregnancy in north Indian population: a pilot study. Int J Reprod Contracept Obstet Gynecol 2016;5:1577-81. 